\title{
Correction to: Fasting in diabetes treatment (FIT) trial: study protocol for a randomised, controlled, assessor-blinded intervention trial on the effects of intermittent use of a fasting-mimicking diet in patients with type 2 diabetes
}

Elske L. van den Burg ${ }^{1 *}$, Marjolein P. Schoonakker ${ }^{1}$, Petra G. van Peet ${ }^{1}$, M. Elske. van den Akker-van Marle², Ko Willems van Dijk ${ }^{3,4}$, Valter D. Longo ${ }^{5,6}$, Hildo J. Lamb ${ }^{7}$, Mattijs E. Numans ${ }^{1}$ and Hanno Pijl ${ }^{3}$

Correction to: BMC Endocr Disord 20, 94 (2020)

https://doi.org/10.1186/s12902-020-00576-7

Following publication of the original article [1], the authors identified the Table 1 is incorrect. The correct Table 1 is as below, and the original article has been corrected.

\begin{abstract}
Author details
'Department of Public Health and Primary Care, Leiden University Medical Center (LUMC), Postzone V0-P, Postbus 9600, 2300 RC Leiden, The Netherlands. ${ }^{2}$ Department of Biomedical Data Sciences, Medical Decision Making, Leiden University Medical Center, Leiden, the Netherlands. Internal Medicine, Leiden University Medical Center, Leiden, the Netherlands. ${ }^{4}$ Human Genetics, Leiden University Medical Center, Leiden, the Netherlands. ${ }^{5}$ FIRC Institute of Molecular Oncology, Milan, Italy. 'Longevity Institute, Davis School of Gerontology, University of Southern California, Los Angeles, USA. ${ }^{7}$ Radiology, Leiden University Medical Center, Leiden, the Netherlands.
\end{abstract}

Published online: 04 November 2020

\section{Reference}

1. van den Burg, et al. Fasting in diabetes treatment (FIT) trial: study protocol for a randomised, controlled, assessor-blinded intervention trial on the effects of intermittent use of a fasting-mimicking diet in patients with type 2 diabetes. BMC Endocr Disord. 2020;20:94 https://doi.org/10.1186/s12902-020-00576-7.

The original article can be found online at https://doi.org/10.1186/s12902 020-00576-7.

* Correspondence: e.l.van_den_burg@lumc.nl

'Department of Public Health and Primary Care, Leiden University Medical

Center (LUMC), Postzone Vo-P, Postbus 9600, 2300 RC Leiden, The Netherlands

Full list of author information is available at the end of the article

(c) The Author(s). 2020 Open Access This article is licensed under a Creative Commons Attribution 4.0 International License, which permits use, sharing, adaptation, distribution and reproduction in any medium or format, as long as you give appropriate credit to the original author(s) and the source, provide a link to the Creative Commons licence, and indicate if changes were made. The images or other third party material in this article are included in the article's Creative Commons licence, unless indicated otherwise in a credit line to the material. If material is not included in the article's Creative Commons licence and your intended use is not permitted by statutory regulation or exceeds the permitted use, you will need to obtain permission directly from the copyright holder. To view a copy of this licence, visit http://creativecommons.org/licenses/by/4.0/ The Creative Commons Public Domain Dedication waiver (http://creativecommons.org/publicdomain/zero/1.0/) applies to the data made available in this article, unless otherwise stated in a credit line to the data. 
Table 1 Example meal plan of the fasting-mimicking diet for study participants

\begin{tabular}{|c|c|c|c|c|c|}
\hline & Day 1 & Day 2 & Day 3 & Day 4 & Day 5 \\
\hline \multirow[t]{3}{*}{ Breakfast } & Tea & Tea & Tea & Tea & Tea \\
\hline & Nut bar & Nut bar & Nut bar & Nut bar & Nut bar \\
\hline & Algal Oil capsule & & & & Algal Oil capsule \\
\hline \multirow[t]{5}{*}{ Lunch } & & Tea & Tea & Tea & Tea \\
\hline & Tomato Soup & Mushroom Soup & Tomato Soup & Vegetable Soup & Tomato Soup \\
\hline & Olives & Olives & Kale Crackers & Olives & Kale Crackers \\
\hline & Kale crackers & & & & \\
\hline & Vitamin capsule & Vitamin capsule & Vitamin capsule & Vitamin capsule & Vitamin capsule \\
\hline \multirow[t]{2}{*}{ Afternoon } & Tea & Tea & Tea & Tea & Tea \\
\hline & Nut bar & Olives & & Olives & \\
\hline \multirow[t]{4}{*}{ Dinner } & & Tea & Tea & Tea & Tea \\
\hline & Minestrone Soup & Quinoa Mix Soup & Minestrone Soup & Quinoa Mix Soup & Minestrone Soup \\
\hline & Choco crisp bar & Choco crisp bar & & Choco crisp bar & \\
\hline & Vitamin capsule & Vitamin capsule & Vitamin capsule & Vitamin capsule & Vitamin capsule \\
\hline During the day & & Syrup for water flavouring & Syrup for water flavouring & Syrup for water flavouring & Syrup for water flavouring \\
\hline
\end{tabular}

